were males and 45 were females. They all recovered. All were the subjects of emotional storms of prolonged duration.

Mental derangement assooiated with gross brain lesions.There were 38 cases under this heading, 28 of the patients being males and ten being females. Some were cases of cerebral hæmorrhage, some of brain tumours, while others were those of syphilitic endarteritis. Two of the patients were sent to asylums, 15 recovered, and 21 died.

Puerperal mania.-This condition was responsible for 25 cases. 21 patients were sent to asylums, three recovered, and one died.

Amongst unclassified cases were the following: one case of a male who was the subject of pernicious anæmia with delusions and who died; another of a male who suffered from locomotor ataxy with delusions and who recovered his mental balance; a third of a male who had contracted the cocaine habit and had suffered from delusions and who recovered; three cataleptic cases among females (one was sent to the asylum and the other two recovered) and two cases of domestic infelicity in which the wife succeeded in sccuring the temporary incarceration of a husband with an ill-regulated temper, both being released after examination.

My object in choosing this subject for my presidential address is to bring to your notice the curability and the temporary nature of the large proportion of mental cases. 50.3 of our cases have recovered; 39.54 only have gone to asylums. As honorary secretary of the lunacy committee of the Metropolitan Workhouse and Infirmary Medical Officers Conference I have collected the figures for London for the last four years.

\begin{tabular}{|c|c|c|c|c|}
\hline \multicolumn{2}{|r|}{ Years. } & Cases. & Sent to asylums. & Cured. \\
\hline 1902 & $\begin{array}{lll}\ldots & \ldots & \ldots\end{array}$ & 8076 & 3920 & 3560 \\
\hline 1903 & $\begin{array}{lll}\ldots & \ldots & \ldots\end{array}$ & 8004 & 3792 & 3443 \\
\hline 1904 & $\begin{array}{lll}\ldots & \ldots & \ldots\end{array}$ & 7654 & 3716 & 3155 \\
\hline 1905 & $\begin{array}{lll}\ldots & \ldots & \ldots\end{array}$ & 7322 & 3583 & 2877 \\
\hline
\end{tabular}

These figures show that so far from lunacy having increased in London it has in four years steadily decreased, being 754 less in 1905 than in 1902, the numbers sent to the asylum from the workhouses and infirmaries being also 337 less. I strongly urge that the Lewisham system should be everywhere adopted and that no case should be sent directly to an asylum, but that all should go through the sifting process of the infirmary half-way house. For cases who are not paupers a difficulty at once arises, for directly an institution be established to deal solely with mental cases, whether in their incipient or later stages, it immediately becomes in the eyes of the public a lunatic asylum and the stigma of lunacy adheres to all who accept its help. The solution is in attaching a mental block to each general hospital, an arrangement beneficial to both the public and the profession. I would discourage the practice which still obtains in a few districts of certification by the family attendant of the justice. I know of one case where a consulting oculist was given a turn at a pauper case in a London workhouse. A strange practitioner, seeing the patient for a few minutes, then and there determining his destination, to the exclusion of the medical officer who has all the available knowledge concerning the individual and all the responsibility of his care and treatment, reduces the working of the Act to a mere farce.

May I, in conclusion, express the opinion that the result we have achieved in Lewisham is one of which we may justly feel proud. It has required, and it has received, the loyal coöperation of all authorities-of the Blackheath bench of magistrates, of the Lewisham board of guardians, and the medical officers and the relieving officers. The knowledge that 1020 persons have been spared from being branded as lunatics cannot be other than a source of gratification to all concerned.

Pharmaceutical Society of Great Britain.The sixty-fifth session of the School of Pharmacy of this society will commence on Monday, Oct. 1st, when the President will present the Pereira medal, and the inaugural sessional address will be delivered by Sir George Watt, M.B., O.M., C.I.E.

\section{SUTURE OF PERFORATING WOUND OF THE HEART; DEATH ON THE ELEVENTH DAY.}

BY FREDERICK T. TRAVERS, B.S. LOND., F.R.O.S. EDIN., HONORARY SURGEON TO THE WEST KENT GENERAL HOSPITAL,

AT 11.30 A.M. on June 21st the patient, an active lad, aged 19 years, after climbing over the surrounding fence, some six feet high, scrambled on to the upper stone of the cromlech known as Kit's Coty House. This stone is about eight feet from the ground and the railings are about three feet distant from it. He attempted to leave by stepping on one of the longer spikes of the fence from the stone. In doing so his foot slipped and he fell forward and was impaled on the spike. He managed to lift himself free and fell inside the fence. Nearly an hour elapsed before medical aid could be obtained or the assistance necessary to lift him on a hurdle over the fence. He was brought to the hospital by Dr. T. A Palm of Aylesford at 2.45 P.M. I saw the patient imme diately after his arrival at the hospital ; his clothing was saturated with blood, he was just conscious, blanched, with small frequent pulse and sighing respiration. There was a transverse wound about two inches in length over the lower end of the sternum, through which a vertical fissure in the bone could be seen. There was little bleeding. (Fig. 1.)

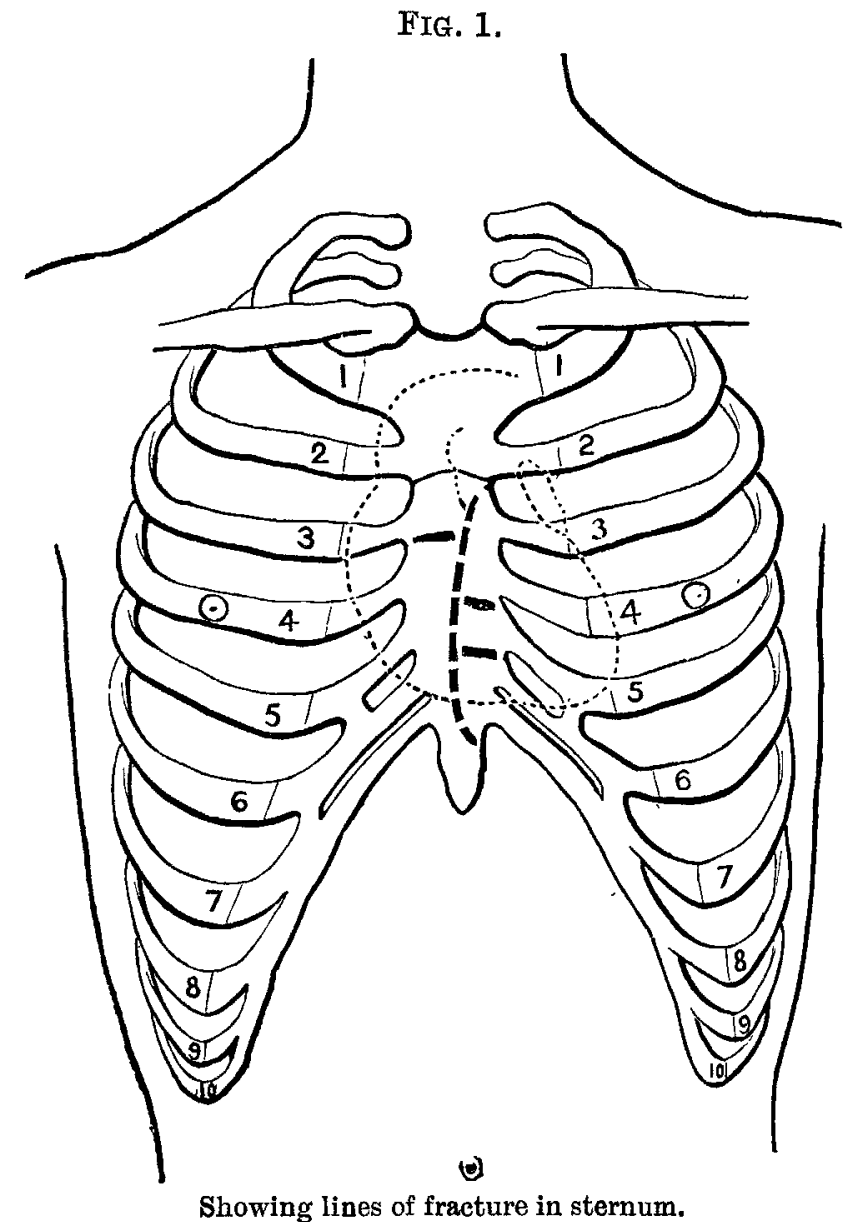

As the account given rendered injury of the structures within the chest probable I thought it advisable to anæsthetise the patient and to explore the wound. Six minims of liquor strychninæe were given subcutaneously, and chloroform was administered. The fragments of the sternum were separated and the finger introduced. A loose piece of bone and beyond it the surface of the heart were felt. The wound was therefore extended by a curved incision from its right extremity, running upwards and then to the left. This exposed the lower half of the sternum on the left side; the vertical fissure extended upwards to the second right costal cartilage and there were fractures through the left half between the fourth and fifth and fifth and sixth costal cartilages; the portion between the second and fifth costal cartilages was missing. The third, fourth, and fifth cartilages were divided at their attachment to the ribs and the lower fragment of the sternum 
was turned downwards. In freeing the third cartilage the pleura was wounded. The rent, about half an inch in length, was at once clipped with artery forceps and closed by two sutures. A rent in the pericardium about two and a half inches in length was now exposed through which blood was slowly escaping. The pericardium was full of blood-clot which was gently sponged away, a piece of bone one inch by half an inch was removed, and a small spicule of bone was felt imbedded in the heart and extracted. On further examination a wound was felt in the right ventricle and on following this along another piece of bone was felt. This was seized with forceps and removed and its removal was followed immediately by a terrific gush of dark blood. I at once plugged the wound in the heart by plunging my fingers in and found that the insertion of three fingers practically stopped the bæmorrhage; I also found that my fingers were within the cavity of the heart, the index being separated from the middle and ring fingers by a band of tissue, which at the time I took to be the anterior flap of the tricuspid valve. Three sutures were inserted, withdrawing a finger as each was passed and by them the wound was roughly drawn together, and then ten sutures were passed through the muscular coats, using the first three, which were left long, to steady the heart and bring the wound into view. A second row of ten Lembert sutures were passed through the pericardial serous coat closing in the first row. The wound was now quite closed and no bleeding was going on. After the first flow of blood transfusion into the saphena vein of the right leg was commenced but was stopped as the immediate increase of blood pressure increased the hæmorrhage. The transfusion was continued when the first row had been tied. The contractions of the heart became very lively as each suture was inserted and but for this somewhat violent stimulus it appeared several times that pulsation would have ceased. The pericardium was cleansed with gauze and partly closed with a row of sutures, the fragment of sternum was replaced, and the wound was closed except at its upper and lower angles. The fragments of the third and fourth costal cartilages, having their sternal ends also datached, were not replaced. The wound was irrigated freely with sterilised water and dressed with double cyanide gauze.

During the operation a second hypodermic injection of six minims of liquor strychninæ were given and at 5 P.M. when the patient was in bed, a further injection of five minims was given; also an enema of saline solution (half a pint) and brandy (half an ounce). His pulse was 116, regular, and of fair force, but small volume. He recovered consciousness by 5.30 P.M. and complained of thirst and was given sips of lime juice and water. At 7 P.M. he was restless and sick. The dressing had come through but was not disturbed. The temperature was $97 \cdot 8^{\circ} \mathrm{F}$. The sickness continued at intervals through the night. On the 22 nd, at 5 A.M., half an ounce of brandy and the white of an egg in half a pint of saline solution were given as an enema and at 7 A.M. three minims of liquor strychninæ. At 8 A.M. the temperature was $100^{\circ}$, the pulse was 116 , and the respirations were 30 . At 9 A.M. the enema was repeated; the patient was rather drowsy. The injection was repeated at 12.30 P.M. and 3.30 P.M. The patient complained of no pain, but a feeling of weight in the chest and slept a few minutes at a time all through the day. The pulserate kept at about from 120 to 130 , but the respiration rate rose at $2.30 \mathrm{P} . \mathrm{M}$. to 72 , falling by $5 \mathrm{P} . \mathrm{M}$. to 61 . The wound was dressed at 7 P.M. There was no hæmorrhage but free serous discharge. He was given an enema of half an ounce of brandy and half a tin of Brand's essence was given in five ounces of saline solution. He slept most of the night quietly, but on waking occasionally would have an attack of restlessness with difficulty in breathing. The enemata were repeated every four hours. At midnight the pulse was 120 and the respirations were 48 . He took sips of water or milk-and-water continually when awake. A few râles were heard over the base of the left lung in the axillary region but no signs of pneumothorax were present. 0 n the 23 rd the wound was dressed at 130 A.M. There was a free serous discharge which was slightly turbid. The respirations were 45 . The pulse was 118 and more thready than ever before; it improved after five minims of liquor strychninæ were given hypodermically. During the night he had six bouts of restlessness, all following the same course, the pulse first becoming thready and more frequent; an attack of dyspncea followed with some pain in the chest, the patient becoming restless for a time. During the day these attacks were slighter and less frequent and he slept most of the time. He was very thirsty and took about three ounces of milk-and-water every hour. On the 24th at 12. $30 \mathrm{~A} . \mathrm{M}$. the pulse was 144 and irregular. The patient was sleeping quietly. He had a fairly comfortable day. There was free discharge from the wound, which was dressed twice. The fluid draining from the wound was serous and evidently pericardial ; the quantity soaking into the dressing was very considerable. At midday there was a very free escape of fluid, and after this his breathing and pulse improved very much and he had no severe dyspnœic attacks during the rest of the day. On the 25th he was still very thirsty and drank milk and albumin water freely. He was sleeping well and quietly, but his breathing was noisy when awake; a few râles were still present. At 3 P.M. he had a slight rigor; the pulse was very thin and 135 per minute. He was given a hypodermic injection of three minims of strychninæ and six minims of tincture of digitalis, and at 4 P.M. the pulse was much improved-126 per minute. On the 26th the patient had passed a very fair night. He was rather faint at 6 A.M. but improved after five minims of liquor strychninæ had been administered hypodermically. 'The wound was dressed at 8 A.M. and 5 P.M. The bowels were freely opened after an enema of soap and water and two drachms of turpentine. He had a comfortable day but perspired freely at times. No râles were to be heard now and breathing was quite easy.

The patient's condition improved a little each day till June 29th. The wound was dressed every eight hours after the $26 \mathrm{th}$ as the lacerated skin and subcutaneous tissue at the site of the original injury appeared likely to slough. On

FIG. 2.

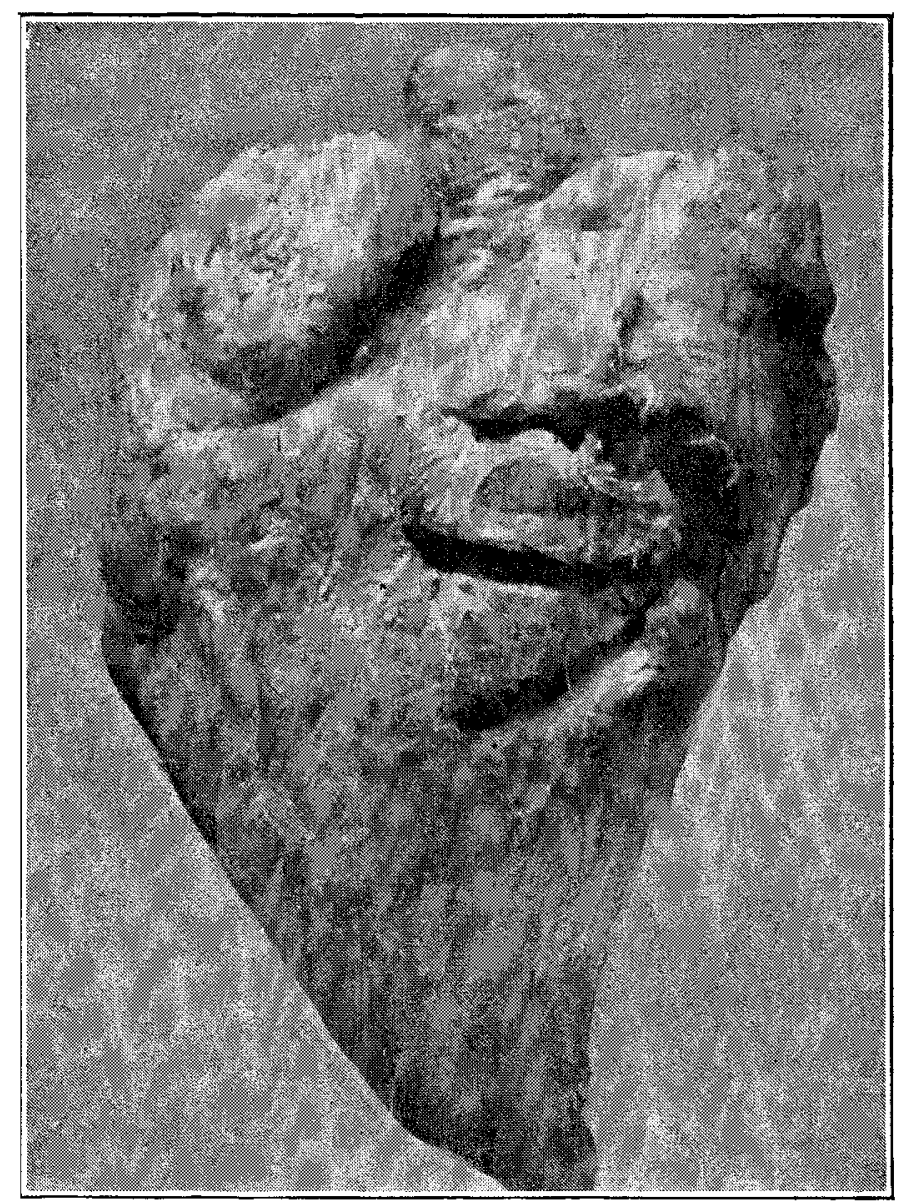

Appearance of heart after removal. The stitches bare been removed and the wound opened up. The left ventricle has been cut away up to the interventricular sept um.

the 28th some of the stitches were removed as they were cutting through the skin. The wound was irrigated at first with biniodide solution 1 in 4000 and later with sterilised water and lightly packed with gauze. On the 29 th the wound was clean and more healthy except at the edges of the fissure in the sternum where there were a good many shreds of necrosing aponeurotic tissues. On the $30 \mathrm{th}$ he had several attacks of faintness and at 11 P.M. there was a little blood on the dressing but no hæmorrhage was apparent on 
removing the gauze. $\mathrm{He}$ became more restless later and wandered a good deal and died at 2.30 A.M. on July 1st.

At 2.30 P.M. on July lst an examination was made of the injuries. On opening up the wound there was some recent lymph seen about the divided rib cartilages. There was no blood or clots. The edges of the fractured portions of sternum were necrotic and a further fracture was found running transversely just below the third costal cartilage. The wound in the pleura could not be found. The pericardial wound, two and a half inches in length, was healed with the exception of about a third of an inch in the centre. On opening up the pericardium a clot was seen covering the heart, partially organised and adhering somewhat firmly to it. This was carefully removed and several ounces of dark fluid blood removed from the pericardium; there was no pus in the sac. The wound in the heart was difficult to determine except at its left and upper extremity, the greater part being covered by smooth lymph. The heart was removed with as little handling as possible. (Fig. 2.) There was some recent and firmly adherent lymph on the auricular appendages, chiefly on the right, around the bases of the great vessels, and on the left ventricle, but little on the right ventricle except about the wound. The wound in the heart was well closed except at a point where a small portion of the muscular wall between two parts of the rent showed signs of necrosis. The rent was trifid externally, or rather one long rent with two lateral branches, and was situated altogether in the right ventricle; in the recent state it measured in length two and a quarter inches and extended right up to the inter-ventricular septum. (Fig. 3.)

Frg. 3.

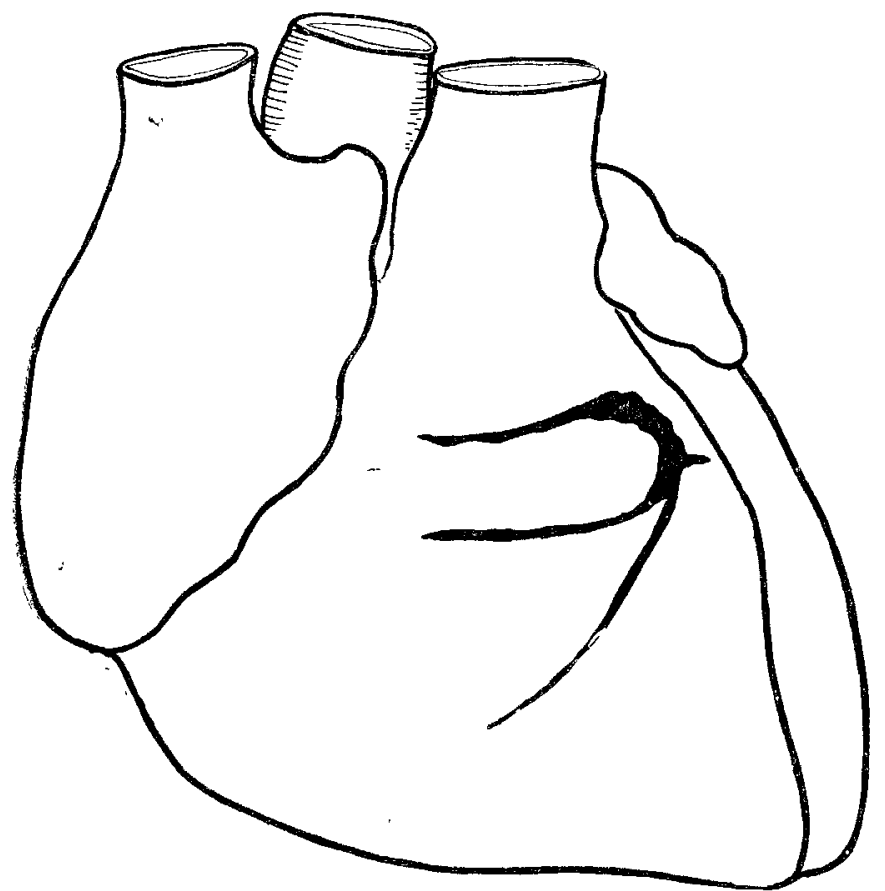

Diagrammatic view of wound. It will be scen that one tear extends to the interventricular septum.

From within the rent appeared to be more irregular and was somewhat )-(-shaped and was only healing at the extremities of the various parts of the rent.

The most noticeable features of the case were the plugging of the wound in the heart by the detached fragment of sternum, which almost entirely stopped the bleeding, and the tolerance shown by the heart to the injury and the handling required at the operation. Pulsation continuer regularly while three fingers were held in the wound with their tips within the cavity of the ventricle. The loss of blood was very considerable even then, but the insertion of each suture was observed to act as a very immediate stimulus, and after the insertion of the first row, when the heart's action had become very feeble, the insertion of the second superficial layer of sutures stimulated its action so that it became more regular and forcible. In view of the enormous loss of blood, it was remarkable that there was so little collapse; there was, further, no air-hunger or delirium, though symptoms of cerebral anæmia were, so far as possible, averted by keeping the foot of the bed well raised. The patient recovered consciousness within balf an hour of being put to bed and was conscious and rational throughout. The severe injury to the pericardium again, though inducing excessive secretion of pericardial fluid, was accompanied by no symptoms, owing to the free drainage afforded to the sac by the incomplete closure of the wound in it. The cause of death was apparently failure of the heart's action due to the pressure of the clot slowly forming on its anterior surface, which also blocked the pericardial wound and prevented the escape of the blood oozing from the gap in the wound in the heart and not directly due to the slight secondary hæmorrhage.

In conclusion, I wish to say that I am much indebted to Dr. Joseph Ward, house surgeon to the hospital, for his assistance in keeping the notes of the case and for his constant attention to the patient during the 11 days he survived the accident.

Maidstone.

\section{A STUDY OF THE STREPTOCOCCI} PATHOGENIC FOR MAN.

BY F. W. ANDREWES, M.D. OxON., F.R.C.P. LOND., PATHOLOGIST TO, AND LECTURER OX PATHOLOGY AT, ST. BARTHOLOWEW'S HOSPITAL, LONDON;

AND

T. J. HORDER, M.D. LOND., F.R.C.P. LOND., MEDINAL REGISTRAR AND DEMONSTRATOR OF MORBID $\triangle$ ITATOMY AT SГ. BAR'THOLOMEW'S HOSPLTAL, LONDON; PHYSICLAN TO THE GREAT NORTHERT CEXTRAL HOSPITAL, LONDON.

\section{Introduction ; Difficulties in Classifying Strepto-} COCCI; GoRdon's Metabolic Tests.

Almost from the time when streptococci were first shown to be connected with certain morbid conditions in man the problem of the identity or non-identity of the types found in different diseases has been actively discussed. One of the earliest disputes concerned the relationship between Fehleisen's streptococcus of erysipelas and that found by Rosenbach in acute suppurations and named by him streptococcus pyogenes. It is now generally conceded that the two organisms are identical, representing at most two differing phases of virulence. In recent years the innumerable bacteriological investigations which have been carried out upon diseased conditions of every kind have shown that streptococci are associated with a large number of acute and chronic inflammatory affections and blood infections, so that to-day they are justly regarded as amongst the most important of pathogenic bacteria. This advance in our knowledge of their importance and commonness in the production of disease has not, however, been associated with any corresponding advance in our power of discriminating between the different varieties of streptococci concerned. With the introduction of serumtherapy the problem has entered upon a more acute phase. Anti-streptococcal serum occasionally works miracles but is more often without effect of any kind, and it has been suggested that one reason for this may be that there are various species of streptococci at work, and that the miracle comes off when by chance the serum has been produced by immunisation with the same organism as happens to be the cause of the disease. The need for some means of discriminating between the different sorts of streptococci has become greater than ever.

Some pathologists, notably Marmorek, to whom we owe the introduction of anti-streptococcal serum, have stoutly maintained the unity of all the streptococci pathogenic for man. Marmorek based his chief argument upon the facts that bouillon in which one sort of streptococcus has grown is incapable of serving as a culture-medium for any other sort and that all alike show similar hæmolytic power. The general demand for a multivalent serum shows that this view has not gained wide credence amongst the medical profession.

There have hitherto been no satisfactory criteria for judging of the specific characters of the various streptococci occurring in disease. Morphology has proved of little value. The size of the individual cocci varies too little to be of service. More hopeful is the length of the chains formed. In 1891 von Lingelsheim proposed a division into two groups based on this criterion; he suggested the terms "streptococcus brevis" for the short-chained forms rendering broth uniformly turbid and for the most part 